\title{
Development and Validation of a Stability Indicating RP-HPLC Method for Balofloxacin
}

\author{
CEEMA MATHEW ${ }^{1}$, M. AJITHA $^{2}$ and P.R.SATHESH BABU ${ }^{1}$ \\ ${ }^{1}$ Gokaraju Rangaraju College of Pharmacy, Osmania University, Bachupally, Hyderabad - 90, India. \\ 2Jawaharlal Nehru Technological University, Hyderabad - 85, India. \\ ${ }^{*}$ Corresponding author E-mail:nirujose@gmail.com \\ http://dx.doi.org/10.13005/ojc/300453
}

(Received: September 26, 2014; Accepted: November 20, 2014)

\begin{abstract}
The present work describes the development of a stability indicating high performance liquid chromatographic (HPLC) method for the determination of Balofloxacin as bulk drug and as pharmaceutical formulation. The drug was separated using Phenomenex $(250 \times 4.6 \mathrm{~mm}, 5 \mu \mathrm{m}$ particle size) ODS column at a flow rate of $1 \mathrm{mLmin}^{-1}$ and a SPD $20 \mathrm{~A}$ UV detector to monitor the eluate at $298 \mathrm{~nm}$. The isocratic method used a mobile phase consisting of methanol and phosphate buffer of $\mathrm{pH} 6.8$ in the ratio 70:30. The linear regression analysis data for the calibration plots showed good linear relationship with $r^{2}=0.9998$ in the working concentration range of $5-100$ $1 / 4 \mathrm{gmL}^{-1}$. The LOD and LOQ were 90 and $273 \mathrm{ngmL}^{-1}$ respectively. The drug was subjected to stress degradation using acid, alkali, hydrogen peroxide, dry heat, wet heat and uv light. The standard drug peaks were well resolved from the degradation products' peaks with significantly different retention time (Rt).
\end{abstract}

Key words: HPLC, degradation, stability-indicating, Balofloxacin (BLFX).

\section{INTRODUCTION}

Balofloxacin (BLFX), chemically named 1cyclopropyl-6-fluoro-1,4-dihydro-8-methoxy-7-(3methylamino-piperidin-1-yl)-4-oxoquinoline-3carboxylic acid, is the fourth generation of a new class of synthetic antibacterial fluoroquinolone agents. It has broad antibacterial spectrum, ranging from gram-positive bacteria to gram-negative bacteria. BLFX exhibited excellent antibacterial activity against gram-positive bacteria such as multiple-drug-resistant staphylococci and pneuropiummococci ${ }^{1=3}$. The methoxy group at the 8-position reduces photoallergic responses ${ }^{4,5}[8,9]$. It is prescribed for infective opthalmitis, sinusitis, chronic bronchitis, pneumonia, skin infections etc. Like other new fluoroquinolones, the bactericidal action of BLFX results from inhibition of the eneymes topoisomerase (II) (DNA gyrase) and topoisomerase $(\mathrm{IV})^{6}$. It was largely excreted via urine as the unchanged chemical constitution. ${ }^{7}$ Different methods have been reported in the 
literature for the analysis of BLFX, based on high performance liquid chromatography, ${ }^{8=10}$ HPLCelectro spray ionization - mass spectrometry ${ }^{11}$, fluorospectrophotometry ${ }^{12}$ and UV spectrophotometry ${ }^{13,14}$. Although these analytical techniques have been successfully applied to analysis of BLFX in pharmaceutical and biological samples, no stability indicating HPLC method is reported so far. As the International Conference on Harmonization (ICH) guidelines require the development of stability-indicating methods (SIAMs) for drug assays in stability tests ${ }^{15}$ in the present investigation a simple stability indicating analytical methodology is developed.

\section{EXPERIMENTAL}

\section{Materials and Reagents}

Balofloxacin API was available as Gift sample from Cirex Pharmaceuticals Ltd, Hyderabad. Methanol, disodium hydrogen phosphate and potassium dihydrogen phosphate were purchased from S.D Fine Chemicals (Mumbai, India) and were of HPLC grade. Hydrochloric acid, sodium hydroxide pellets, hydrogen peroxide and orthophosphoric acid were purchased from S.D Fine Chemicals (Mumbai, India) and were of A.R grade.HPLC grade water was prepared in house by distillation of water in triplicate followed by filtration through filter paper of $0.45 \mu \mathrm{m}$ pore size and $47 \mathrm{~mm}$ diameter.

\section{HPLC Instrumentation and Chromatographic} Conditions

The HPLC system consists of a Shimadzu LC 20 AD binary pump and SPD 20 A UV detector. The column consists of Phenomenex $(250 \mathrm{~mm}$ length, $4.6 \mathrm{~mm}$ internal diameter, $5 \mu \mathrm{m}$ particle size) ODS. LC Solution software was used for data acquisition. Sample injection was done by Rheodyne manual Injector. Chromatographic separation was achieved using Phenomenex ODS column. The LC system was operated isocratically using a mobile phase consisting of a mixture of methanol and phosphate buffer of $\mathrm{pH} 6.8$ (prepared with $5.04 \mathrm{~g}$ of disodium hydrogen phosphate and $3.01 \mathrm{~g}$ potassium dihydrogen phosphate dissolved in $1000 \mathrm{~mL}$ of triple distilled water) in the ratio of $70: 30$ as the mobile phase at a flow rate of $1.0 \mathrm{~mL} /$ min at room temp. The injection volume was $20 \mu \mathrm{L}$ for both standard and sample. The UV detector was set at $298 \mathrm{~nm}$ and the peak area integration was done using LC solution software.

\section{Preparation of Balofloxacin standard}

The stock solution of BLFX was prepared by weighing $10 \mathrm{mg}$ of the reference substance and transferring to a $10 \mathrm{~mL}$ volumetric flask, diluting to $10 \mathrm{~mL}$ with methanol $(1000 \mu \mathrm{g} / \mathrm{mL})$. The working standard solution $(100 \mu \mathrm{g} / \mathrm{mL})$ was obtained by dilution of the stock solution using mobile phase.

\section{Preparation of sample solution}

Tablets containing $100 \mathrm{mg}$ of BLFX were accurately weighed and crushed to fine powder. A quantity of powder equivalent to $25 \mathrm{mg}$ of BLFX was transferred to a $25 \mathrm{~mL}$ volumetric flask and added $10 \mathrm{~mL}$ of methanol, kept in an ultrasonic bath for $10 \mathrm{~min}$ and made upto the volume with methanol and filtered.

\section{Validation study}

The developed method was validated as per ICH guidelines using BLFX with respect to the following parameters: accuracy, precision, LOD, LOQ, specificity, robustness, stability and system suitability.

\section{Linearity}

For testing linearity seven calibration standards were prepared in the range of 5 to 100 $\mu \mathrm{g} / \mathrm{mL}(5,10,20,40,60,80$ and $100 \mu \mathrm{g} / \mathrm{mL})$. Standard curve was obtained by plotting peak area against concentration and the evaluation of linearity was done by linear regression analysis using least square method.

\section{Limit of detection and limit of quantitation}

Limit of detection (LOD) and limit of quantitation (LOQ) were estimated at a signal to noise ratio of 3:1 and 10:1 respectively by injecting a series of dilute solutions of known concentration.

\section{Specificity}

Specificity is the ability of a method to measure analytical response in presence of its potential impurities. Specificity of the method was carried out by the deliberate degradation of the drug by oxidation, heat, hydrolysis (acidic, alkaline, neutral) and photolysis, followed by its analysis using the developed method. 


\section{Accuracy}

Accuracy of the developed method was assessed in triplicate at three concentration (40, 60 and $80 \mu \mathrm{g} / \mathrm{mL}$ ). The percentage recovery was calculated from the linear regression equation obtained in the linearity studies.

\section{Precision}

The precision of the analytical method was evaluated by the determination of the repeatability of the method (intra day precision) and intermediate precision (inter day precision) of the sample solutions. Repeatability was calculated by assaying six samples prepared on the same day. Intermediate precision was calculated by assaying 3 days. The relative standard deviation of the area of peaks was calculated.

\section{Robustness}

Experimental conditions were deliberately altered, in order to determine the robustnes. From the different experimental conditions such as flow rate $(1.0 \mathrm{~mL} / \mathrm{min})$, lambda $\max (298 \mathrm{~nm})$ and percentage of methanol (70), each selected factor was changed at three levels $(-1,0,+1)$. One factor was changed at a time to study the impact of the change in the experimental conditions on the assay results. Change in the peak area and the retention time were noted at each change in the analytical parameters.

\section{Stability of sample solution}

Sample solution was prepared and analysed by the HPLC instrument using fresh mobile phase at different time intervals $(0 \mathrm{~h}, 8 \mathrm{~h}$ and $24 \mathrm{~h})$.

\section{RESULTSAND DISCUSSION}

\section{Optimization of chromatographic condition}

The chromatographic conditions were optimized with a view to obtain symmetrical peak of BLFX. At the same time the peak should be well separated from the degradation peaks so that it can be quantified even in presence of degradants. Separation was achieved using a mobile phase consisting of methanol and phosphate buffer of $\mathrm{pH}$ 6.8 in the ratio of 70:30 by an isocratic profile, at a flow rate of $1 \mathrm{~mL} \mathrm{~min}^{\prime \prime}$. UV detector wavelength was set at $298 \mathrm{~nm}$. The drug was getting eluted at $3.67 \mathrm{~min}$ and the corresponding chromatogram is given in figure 1.

Table 2: Intra- and inter-day precision

\begin{tabular}{|c|c|c|c|c|c|c|}
\hline \multirow[t]{2}{*}{ Con. $\left(\mu \mathrm{gmL}^{-1}\right)$} & \multicolumn{3}{|c|}{ Intraday precision ${ }^{a}$} & \multicolumn{3}{|c|}{ Interday precision ${ }^{b}$} \\
\hline & Mean con. & SD & \%RSD & Mean con. & SD & \%RSD \\
\hline 20.0 & 20.73 & 0.301 & 1.453 & 20.624 & 0.235 & 1.139 \\
\hline 40.0 & 39.991 & 0.233 & 0.582 & 39.757 & 0.455 & 1.144 \\
\hline 80.0 & 81.048 & 0.182 & 0.224 & 80.795 & 0.314 & 0.388 \\
\hline
\end{tabular}

${ }^{a}$ Mean concentration of six trials ${ }^{b}$ Mean concentration of nine trials

Table 3: Data for Recovery studies

\begin{tabular}{lccccc}
\hline Brand & $\begin{array}{c}\text { Spiking level } \\
(\%)\end{array}$ & $\begin{array}{c}\text { Theoretical } \\
\text { content (mg) }\end{array}$ & $\begin{array}{c}\text { Amount found } \\
(\mathbf{m g})\end{array}$ & Recovery (\%) $^{\mathrm{b}}$ & \%RSD $^{\mathrm{c}}$ \\
\hline \multirow{3}{*}{ Baloforce } & 80 & 16 & 16.509 & 101.414 & 1.631 \\
& 100 & 20 & 19.702 & 99.254 & 0.917 \\
& 120 & 24 & 24.527 & 101.197 & 1.283 \\
\hline
\end{tabular}

\footnotetext{
${ }^{a}$ Mean of three determinations $(n=3)$
} 


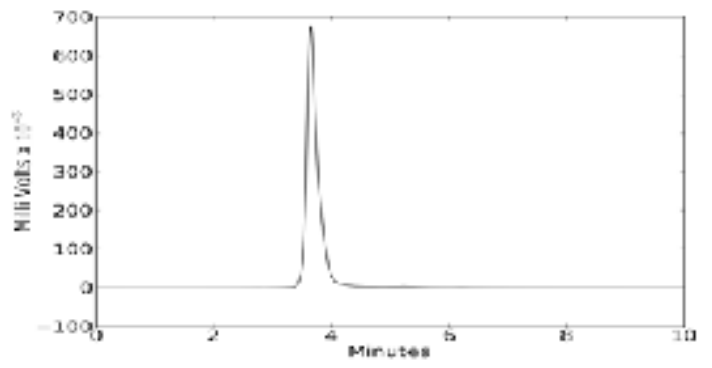

Fig. 1: The chromatogram of BLFX standard

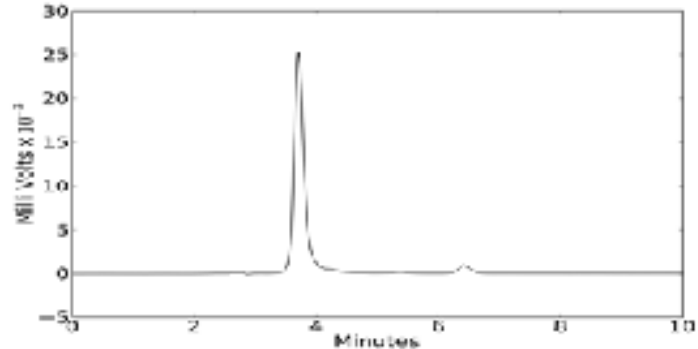

i. Chromatogram for thermal degradation

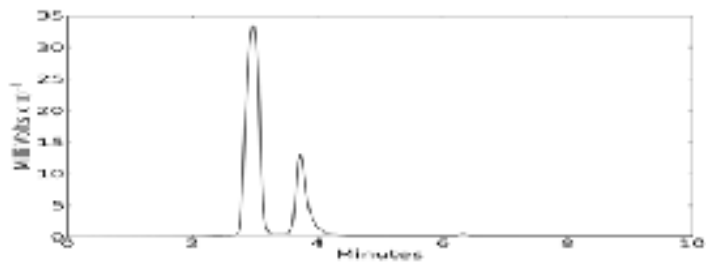

iii. Chromatogram for oxidative degradation

\section{Limit of detection and limit of quantitation}

Concentrations of LOD and LOQ were found to be 90 and $273 \mathrm{ng} / \mathrm{mL}$ respectively.

\section{Linearity}

The regression equation for the graph is $\mathrm{y}=91057$ $x+43149$ and the correlation coefficient, $R^{2}$ is 0.9998 showing excellent correlation between the area and the concentration.

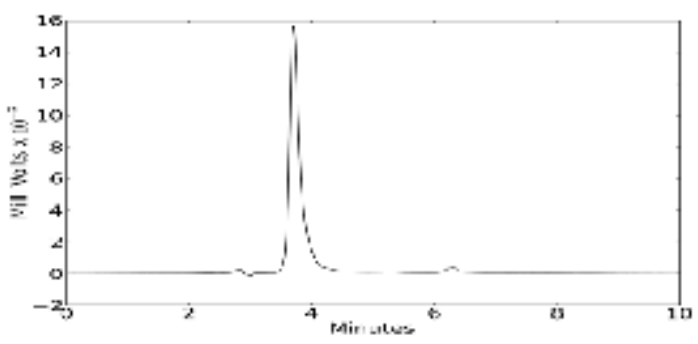

ii. Chromatogram for alkaline degradation

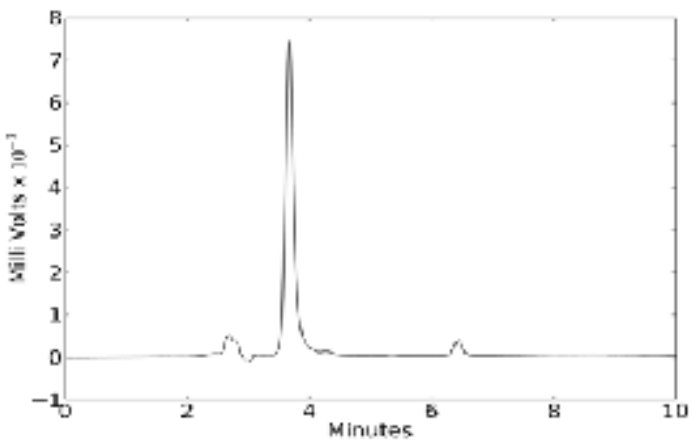

iv. Chromatogram for acidic degradation

Fig. 2: Chromatogram of BLFX along with the degradation products under different stress onditions

\section{Precision}

The percentage relative standard deviation (\%RSD) of the area of BLFX during intra day study was found to be less than 1.5 and for inter day study was found to be less than 1.2 which indicated a good precision of the method (Table II).

\section{Accuracy}

The quantitative recovery of BLFX achieved was ranged from 99.280 - $101.524 \%$ with a low \% RSD value. The results of the recovery experiments done at 3 concentration levels and the $\%$ RSD values are given in Table III.

\section{Analysis of the marketed formulation}

The validated method was applied for the assay of BLFX in 2 brands of Balofloxacin tablets (Baloforce - 100mg, Balotero - 100mg) (Table IV). Due to the absence of extra peaks in the chromatogram, it can be concluded that there was no interference from the excipients in the formulations. The percentage assay values were 
found to be 100.181 and 100.850 for Baloforce and Balotero respectively.

\section{Robustness}

The results in the robustness study, as shown in table $\mathrm{V}$ indicated that the results are not much affected by the small variations in the selected parameters.

\section{Specificity}

In order to check the specificity of the proposed method, degradation studies were carried out by using acidic, basic, photolytic, oxidative and thermal conditions. The drug was stressed under various conditions to conduct forced degradation studies. Intentional degradation was performed by subjecting it to various stress conditions of acidic $(1 \mathrm{~N} \mathrm{HCl})$, basic $(0.1 \mathrm{~N} \mathrm{NaOH})$, neutral (water), oxidative $\left(3 \% \mathrm{H}_{2} \mathrm{O}_{2}\right)$, thermal (heated at $105^{\circ} \mathrm{C}$ ) and photolytic degradation (exposed to UV radiations of $254 \mathrm{~nm}$ for a period of $48 \mathrm{hrs}$ ) to evaluate the ability of the proposed method to separate BLFX from its degradation products. The dug was found to be stable to photolytic and neutral degradation. The results of stress degradation studies are given in Fig.2.

\section{CONCLUSION}

A simple and fast stability indicating HPLC method has been developed and validated for the determination of BLFX in API and different pharmaceutical formulations. The method is accurate, precise, and specific and also has the ability to analyse the drug in presence of its degradation products and it can be employed as a stability-indicating assay. Since the drug peak was well separated from degradation products' peaks it can be employed as a stability indicating method.

\section{REFERENCES}

1. Alksne, L. Curr Opin Investig Drugs. 2003, 4, 224.

2. Ito, T.; Otsuki, M.; Nishino, T. Antimicrob Agents Chemother. 1992,36, 1708.

3. Marutani, K.; Matsumoto, M.; Otabe, Y.; Nagamuta, M.; Tanaka,K.; Miyoshi, A.; Hasegawa,T.; Nagano, H.; Matsubara, S.Kamide, R. Antimicrob Agents Chemother. 1993, 37, 2217.

4. Matsumoto, M.; Kojima, K.; Nagano, H.; Matsubara, S.; Yokota, T. Antimicrob Agents Chemother. 1992, 36, 1715-1719.

5. Gohara, Y.; Arai, S.; Akashi, A.; Kuwano, K.; Tseng, C.C.; Matsubara, S.; Matumoto, M.; Furudera, T. Antimicrob Agents Chemother. 1993, 37,1826-1830.

6. Ito, T.; Kojima,K.; Koizumi,K.; Nagano,H.; Nishino, T. Biol Pharm Bull. 1994, 17, 927930.

7. Kozawa, O.; Uematsu, T.; Matsuno, H.; Niwa, M.; Nagashima, S.;Kanamaru, M. Antimicrob Agents Chemother. 1996, 40, 2824.

8. Nakagawa, T.; Ishigai, M.; Hiramatsu, Y.; Kinoshita, H.; Ishitani, Y.; Ohkubo, K.; Okazaki, A. Arzneimittel for schung Jun 1995, 45
716-718.

9. Deng, J.; Xiao, Z.; Zhang, H.; Zhang, M.; Tang, T. Se Pu. 2007, 25, 942-943.

10. Mi Yaxian, Wu Yan, Li Hualong, Li Lijian. Tianjin Pharmacy, 2008, 5, 10-12.

11. Singh, A.; Khan, MH.; Orient.J.Chem, 2014 , 30(1), 395-399.

12. Bian, Z.W.;Tian, Y.; Zhang, Z. J.; Xu, F. G.; Li, J. H.; Cao, X. M. J Chromatogr B Analyt Technol Biomed Life Sci. 2007, 850, 68-73.

13. Fang Zhao, Yu Qi, Wei Xiong. Chemiluminescence Bull Korean Chem Soc. 2012, 33, 204

14. Ashok Reddy, S.; Chandra Sekhar, K.B. Journal of Global Trends in Pharmaceutical Sciences. 2012, 3, 647-655.

15. Punam, M.T.; Vandana, B.P. International Journal of PharmTech Research 2011,3, 1938-1941.

16. $\mathrm{ICH}$., Stability testing of new drug substances and products (Q1AR). International conference on harmonization, IFPMA, Stability Testing of New Drug Substances and Products:Geneva, 2000. 